\title{
On Perhaps Becoming What You Had Previously Despised: Psychologists as Prescribers of Medication $^{1}$
}

\author{
Kenneth M. Adams ${ }^{2,3}$ and Linas A. Bieliauskas ${ }^{2}$
}

The authors contend that organized psychology's efforts to gain limited prescriptive privileges may be misguided. The modification of psychology's traditional scope of practice may produce harm in the form of lessened patient regard, devaluation of nonpharmacologic elements of practice, and markedly increased exposure to claims of malpractice. The authors also decry the disingenuous use of psychopharmacologically "underserved" populations as rationales for the pursuit of prescriptive privileges. Psychology may mount a major effort to make this change without sufficient justification, in the view of the authors.

KEY WORDS: prescription drug; psychopharmacology; psychology, clinical; psychology, medical; credentialing; malpractice; legislation, pharmacy.

\section{WHAT HAS HAPPENED?}

In our previous lives as graduate students and interns, we recall being exhorted to avoid the "medical model" in dealing with our patients. Maher (1966) even states, "Thus, the more usual physician-patient relationship of physical medicine is often inappropriate for the task of changing deviant behavior and may even mitigate against it" (p. 30). In particular, we recall being taught to not regard behavioral deviations as diseases which represent

'This paper is based in part upon a presentation made at the American Association of Applied and Preventive Psychology (AAAPP) in Washington, DC, June 17, 1991.

${ }^{2}$ Departments of Psychiatry and Psychology, University of Michigan, and Psychology Service, VA Medical Center, Ann Arbor, Michigan.

${ }^{3}$ To whom correspondence should be addressed at Psychology Service (116B), 2215 Fuller Roads, VA Medical Center, Ann Arbor, Michigan 48105-2300. 
"pathology" which may respond to "therapies." From a more pithy perspective, we were cautioned that we should not emulate "pill pushers," who provide some symptomatic relief without effectively changing the behavior of our clients for the better or significantly improving their lives.

Now a number of psychologists (upwards of $60 \%$ as described in various surveys) are interested in providing training to psychologists such that they could prescribe psychoactive medications and advocate a "national agenda" to this end (DeLeon, Fox, \& Graham, 1991). We are somewhat troubled by this seeming turnaround in the perspective of the medical model and the "therapy" of psychological "patients" with a treatment modality which psychologists previously regarded as alien.

As a personal observation, we can say that many psychologists' minds are not completely made up about this issue. They remain open to this notion of prescription privileges and would be willing not only to be persuaded that it is of value, but to invest some considerable personal effort in learning to do it if necessary. The trouble is that it is not clear at this time that the privilege of prescribing medications is viable or valuable for psychology. We ground this sort of current perception in our over 20 years of experience in various medical settings extending back to graduate school. We have worked in medical/surgical, psychiatric, rehabilitation, and geriatric settings. In all of these environments, teaching and research have played a role, and we have been privileged to work with colleagues in various branches in medicine whose prescribing behaviors run the gamut of what is going on in the medical world. One of us (K.M.A.) also enjoyed a faculty appointment stint at a university medical center in Ontario, Canada, and has some first-hand observations about how life really is in that delivery system as well, as it is often held out as a model of how our public health delivery system should work with respect to medicine.

Our general impression is that as one gets closer and closer to the nature of medicines and prescribing, the appeal as the primary care modality with respect to mental health becomes less and less. This is a trend that seems to replicate in our own informal surveying. Like many things, the more you know about it, the more you see the strengths and weaknesses. We see that in the evolving debate on prescription privileges, the most vocal proponents are often those with the least experience in positions that would give them first-hand chances to see the successes and miscues that current prescribers experience. Psychologists who have worked in clinic settings have also observed that quite often the psychiatrist on the team resents being forced into a role of pharmaceutical vending machine. We have had psychiatric colleagues bemoan the fact that they really do not feel as if they are practicing medicine anymore and, certainly, feel that their psychotherapeutic skills are atrophied from disuse. 


\section{THE NATURE OF PRESCRIBING}

There are a number of reasons for our general impression concerning psychologists and prescription privileges and we would like to offer them for your consideration.

First, to prescribe well in a sense of quality of care is a difficult enterprise. We happen to think that psychiatry is an extraordinarily worthwhile medical career choice and one whose promise is very challenging for the trainee to realize. Making the best of biological psychiatry in terms of effecting behavior change is a very difficult intellectual goal. As a result of this difficult target and other influences in educating people to deliver psychiatric services, we would say that the skill level of practice is not at all what it could or should be in the psychiatric community at large. We may be biased in that we are privileged to work with psychiatric colleagues who are master clinicians and "cutting-edge" researchers in the area of psychopharmacology. Even for those doing very good work in this regard, there is a knowledge base that is shifting and changing at a rate that would challenge anyone to keep up.

In response to intimations that psychologists might be interested in this kind of work, a number of reports and guidelines have been published suggesting what a "model" prescribing curriculum might be for psychologists to be able to engage in this activity. One particularly good one is the American College of Neuropsychopharmacology (ACNP) report (Glick, Janowsky, Salzman, \& Shader, 1990). These kinds of guidelines are largely good sets of standards and could very profitably be used actually to evaluate and improve the training and skills of those currently engaging in prescribing behavior now-much less in an enhanced or expanded provider panel. We would hazard to guess that a substantial number of licensed practitioners in psychiatry might not be able to demonstrate the competencies suggested in these model standards.

Another closer concern for us in considering the substrate question is the lack of fully satisfactory information concerning the mechanism and sites of action of the drugs most likely to be used. While there has been clear progress in psychopharmacology for the past three or four decades, the general role of psychopharmacology is as of yet still a palliative and symptom control one. Psychopharmacology is not curative and is unlikely to be so for the immediate future. This is rather a different situation than for other prescribing areas such as infectious disease, for example, where dispensing often has a more curative purpose. This state of affairs does not exist because pharmaceutical companies and organized psychopharmacology are indolent and dull. Those of us in the psychological profession who know something about neurochemistry and behavior realize how hard 
it is to design effective agents. This issue needs to be kept prominently in mind in considering what one might want or might not want to do in terms of acquiring new care modalities. Of course, it goes without saying that the psychoactive drugs which psychologists are interested primarily in prescribing have wide ranging effects on and interactions with multiple physiological systems. For example, let us consider a commonly prescribed antidepressant, Norpramin. How many psychologists are genuinely concerned with this drug's potential for interaction with alcohol, sedative-hypnotics, or other CNS depressants? How many will take regular blood tests to check for the changes in glucose that this medication can produce? How many psychologists know what glucose is? There is far more to prescribing than symptom amelioration.

With respect to the current level of care and people's access to it, it would be hard to characterize as acceptable the ways in which older patients in particular are treated with drugs from a general practice or psychiatric perspective. However, pointing fingers at medicine or psychiatry would not really be fair, since treatment of the elderly, the sick, the infected, or the defective is our society's collective shame these days. We are afraid that we have failed to see the magnitude of our mental health needs as a society in context, and shedding what appear to be crocodile tears about the mentally ill without access to care or coverage has become somewhat of a national sport in televised hearings on C-Span and legislative assemblies around the country. We are not the only profession trying to use the disadvantaged to advantage, and we draw no comfort from the fact that organized psychiatry on the national level sometimes looks even more pretentious than psychology in playing at being socially conscious and politically correct.

Our questions about health care delivery with respect to psychopharmacology in the elderly would also extend to a query about the range of psychopharmacological agents which are actually appropriate and efficacious in the geriatric patient. We frankly do not see much being done in psychopharmacology for seniors beyond "air strike" potency treatment for disruptive patients and crop-dusting for sleep disorders being done in nursing home care environments. Where are the marvelous tools that are going to enable us to deal in a curative fashion with things such as Alzheimer's disease at this time? What sorts of education will enable psychologists to use, deftly, agents such as tricyclic antidepressants which have such complex effects and cardiovascular risks?

Quality of care with respect to psychopharmacology is not what it should be generally in psychiatry and medicine. This is not news to these professions and we doubt strongly that much is accomplished by pointing this out with an arrogant subliminal message that we psychologists could 
do it better (or at least as well). We are quite certain that the quality of psychopharmacological care in certain public institutions such as state hospitals and nursing homes is liable to be lower than in independent practice or private institutions. There is occasionally a simple calculus of personnel, with off-brand medical qualifications and dubious-if any-residencies making a shaky foundation for psychopharmacological practice in too many institutions. We are willing to allow that patients deserve better, but we guess that we are just not ready to volunteer our profession as being intrinsically better at this element of care. We will also allow that in some centers it would be hard to be worse.

There is another aspect of the push for prescription privileges that is a bit touchy because it is just plain economic in scope. Why are we as a profession so eager to get into public-sector prescribing when the economics are so dismal? Are we not trying to reserve a deck chair on the Titanic in this respect? Many psychiatric colleagues we know and respect are having a devil of a time finding ways to treat publicly financed and now even private insurance patients. Reimbursement is absolutely dismal and the states and insurers collectively have decided to play a game of fiscal chicken with healthcare institutions and providers, simply dumping professional and economic responsibility into their laps unbidden. Costs are claimed to be the culprit, but we do not see providers being better off economically in proportion to the "increased costs." Be these things as they may, any observer of outpatient and especially inpatient settings featuring psychopharmacology will also see the tremendously increasing acuity and insistence that stays and density of care be continuously reduced. Anyone seriously trying to provide quality assessment and/or treatment to patients at the rates compensated by Medicaid will predictably cut corners in services, refuse to treat, or even in the case of a few misguided individuals, simply cheat.

The force fields of economics are changing in other respects to that relevant for prescription privilege for psychologists. Managed care is becoming the norm in services in general, and certainly mental health is getting its full share of finished models being put in place-ready or not. The managed care mode of service delivery for mental health promises to build on trends that have already been evolving in recent mental health reimbursement. Inpatient days are likely to become even harder to justify and stays even shorter in duration. It is no longer feasible in the reimbursement environment now evolving to really try to create a therapeutic milieu or logically take a patient through a hospitalization designed to deal correctly or comprehensively with the problems that resulted in admission. Bluntly, psychotherapy is disappearing in our inpatient units. Rather, where inpatient care is justified, it will be simply to weather the worst of the storm and return the patient to the community no longer in a state of complete 
collapse. The key to even hoping to do this successfully is continuity of care, but there is not sufficient discussion of this concept in most managed care models being implemented. Another clear trend is likely to be use of urgent or emergent care facilities to try to weather the worst of the storm and return the patient to the custody of the family-if they have one-with some fantasied hope that they will pursue outpatient treatment.

On the emergency treatment front, psychopharmacology would have an obvious appeal in terms of more immediate control of patient violence or disorganization, but we frankly do not see psychologists or psychiatrists lining up to do this sort of work. It is necessary, but dirty and hard. The emergency room may be a glamorous place for television dramas, but in real life there are few takers for this type of posting in most health systems, public or private. Staff or faculty who do good work in such settings are extraordinarily valuable.

\section{POLITICALLY CORRECT MOTIVATIONS}

Another oft-used reason for psychologists to be in the business of prescribing has to do with underserved populations and the problems of access. We hope that we as a profession do not really mean to come into hearing rooms in state capitals or Washington with a straight face and try to sway lawmakers that it is our major intent and fondest wish to treat the poor, the disadvantaged, people of color, or others who seemingly get less than their due of mental health resources. We doubt, for example, that upon enactment of this prescription privilege legislation, we will see bus loads of psychologists leaving to set up new practices in Wounded Knee, South Dakota, the South Bronx, or the Cass Corridor in Detroit. It is probably reasonable not to be totally cynical about every interest group that appears backing legislation favorable to it; but the public and its representatives are likely to be more than a bit cautious in listening to us describe societal needs that just happen to be financially remunerative.

The corollary with respect to poor standards of practice in psychopharmacology by currently licensed groups has to do with how we would behave as providers of these services. Is there any reason to think that the variability among psychologists in terms of the use of psychoactive drugs would be any different from that of currently licensed providers? There are some providers who are relatively heavy prescribers, while others may use medicine selectively or not at all in some cases. This variability gives rise to yet another source of public concern regarding psychoactive drugs. At the present time, many individuals needing mental health services select psychologists precisely because the psychologist does not utilize psycho- 
pharmacology (whether or not it is a wise decision). People are increasingly skeptical of things that they put in their body in the form of food or drugs, and introducing the prescription privilege would add a new source of concern for patients in terms of their evaluation of providers. This would become even more confusing in the instance that we create a subdivision of the profession based on those who had the prescription privilege and those who did not. At this particular point, we will not focus on the liability problem as it is so obvious as to be not worthy of much comment. Our exposure and malpractice premiums will increase manyfold. We will never really be in the malpractice insurance stratosphere, but we would go from a presently modest coverage to a new order of risk. There are likely to be limits on malpractice and tort settlements more generally introduced in society, but we really must expect that if we are going to treat all of the needy persons that we claim we are, there will be some small proportion of mistakes and those injured thereby will want to have their day in court.

\section{PRESCRIBING AS A SIMPLE COMPETENCY}

Perhaps the most compelling thing that we need to consider at this point is the impact of the argument that "prescribing is a simple competency" that is a matter of training by brief course or workshop. We happen to think that this is nonsense if one really is interested in quality of care in psychopharmacology. Regardless of whether one thinks this is true or not in relationship to psychopharmacology, it really means that we should expect the same argument introduced to us with respect to other services that we currently provide, including things such as psychological testing and treatment. If a psychologist can take a brief course and learn how to prescribe, why cannot an occupational therapist do the same thing with respect to psychological testing and be fully capable of setting up a MMPI evaluation service?

We imagine that for many of our friends who might want prescription privileges, there would be no shortage of huffing and puffing about the kind of development and incursion into psychological practice described just above. Many psychologists are justifiably angry when psychiatrists with no training in measurement or psychological testing start their own testing shops with no training, but a computer printout mill. Arming psychologists with prescription pads after being blessed as 6-week wonders strikes us as equally objectionable. The bottom line is this-How would we reasonably take a position to oppose incursions into our own profession if we simply claim that every professional skill in our portfolio is a simple competency that can be earned like Cub Scout merit badges? Or do we go to a more 
intermediate model involving what is done in martial arts? Could one have a green belt in family therapy, a black belt in psychological testing, or a brown belt in psychopharmacology?

Humor aside, if we do decide to take this "no big deal" position regarding psychopharmacology, we can expect the same logical argument turned on us. We personally have a lot of problems with the "simple competency" model, although we are thoroughly in favor of evaluating, certifying, and recertifying professional competencies such as they now exist. If we are serious about keeping current and keeping professional misfits off the licensure street, this is the way to go. We think that the public, however, will simply demand that professions be done with a very solid pedagogic base and not simply left to vagaries of competing claims in a particular area. The legislative public is already sick and tired of psychology and psychiatry coming to hearing rooms at each other's throats. They have no skills to understand who may be "right" or "wrong" about the particular instant issue, but they are likely to act in a way that will leave at least one party-and perhaps both-disappointed. It strikes us as unwise professionally, unsound scientifically, and ruinous politically to continue to proceed in our bumptious ways with respect to early cheerleading for a jihad with the American Psychiatric Association or even the American Medical Association on the prescription issue. One would think that we as organized psychologists do not have enough to do in cleaning and improving our own clinical, educational, and research houses when in fact the proliferation of low-level training programs is threatening to deflate that respect which our profession has fought so hard to acquire.

We would urge caution, consideration, and consultation on this issue. If there are problems unique to the delivery system for mental health care, say, in the Federal Indian Health Service or remote military installations, these problems could be compassionately considered and solved without using the underserved as a pretext for a theoretically naive and practically self-destructive campaign. We have yet to hear a cogent case to proceed with creating prescription privilege legislation, and the dominant focus in statements and papers written by proponents is on the nature of current legislation granting prescribing rights. These legislatively adept individuals point out that the laws could indeed be changed to include a psychologist's prescription privileges without bringing down the temple of organized health care. This focus misses the whole point. Of course laws could be changed. We could press for legislation making us certified public accountants, jumbo jet pilots, neurosurgeons, or professional sports agents. The entire question is whether laws should be changed to provide psychologists prescription privileges under certain conditions. We are as yet unpersuaded on this particular issue and feel that our mentors may have been correct 
in urging us to behave as psychologists and behavioral scientists, not the purveyors of balms and potions.

\section{REFERENCES}

Glick, I. D., Janowsky, D. S., Salzman, C., and Shader, R. I. (1990). A model psychopharmacology curriculum for psychiatric residents, Ad Hoc Committee of the American College of Pharmacy.

DeLeon, P. H., Fox, R. E., and Graham, S. R. (1991). Prescription privileges. Psychology's next frontier? American Psychologist, 46, 384-393.

Maher, B. A. (1966). Principles of psychopathology. New York: McGraw-Hill. 